\title{
Polyamines and Ornithine Decarboxylase Activity during Growth and Differentiation in Sclerotium rolfsii
}

\author{
By RONI SHAPIRA, ${ }^{1}$ ARIE ALTMAN, ${ }^{2 *}$ YIGAL HENIS ${ }^{1}$ \\ AND ILAN CHET ${ }^{1}$ \\ Departments of Plant Pathology and Microbiology ${ }^{1}$ and Horticulture ${ }^{2}$, \\ The Otto Warburg Center for Biotechnology in Agriculture, \\ The Hebrew University, Rehovot 76100, Israel
}

(Received 26 October 1988; revised 5 January 1989; accepted 12 January 1989)

\begin{abstract}
Changes in polyamine content and in the activity of ornithine decarboxylase (ODC) were followed during growth and differentiation of the plant pathogenic fungus Sclerotium rolfsii, in submerged mycelium liquid cultures and on solid agar cultures. Mycelial growth in submerged cultures was characterized by high putrescine content and ODC activity. Growth cessation, resulting from glucose exhaustion in the medium, was accompanied by a sharp decrease in putrescine content and ODC activity. Spermine, the level of which was initially low, was detected in high amounts after all of the glucose was consumed and when the fungus developed the potential for sclerotium formation. A decrease in spermidine, and especially putrescine content, and an increase in spermine content, were observed during the transition from mycelium to mature sclerotia on solid agar medium. Addition of spermine to solid agar medium increased the number of sclerotia by $40 \%$. The changes in the content of the three polyamines were reversed when sclerotia were allowed to germinate. Moreover, $\alpha$-difluoromethylornithine, the enzyme-activated inhibitor of ODC, greatly inhibited mycelium growth, sclerotium germination and ODC activity, and this inhibition was completely reversed by the addition of putrescine. Cycloheximide delayed sclerotium germination and initially inhibited ODC activity, but ODC inhibition was relieved as soon as sclerotia began to germinate. The data indicate that specific changes in polyamines are linked with two distinct developmental events in $S$. rolfsii. Mycelial growth and sclerotium germination are positively correlated, and possibly causally linked, with a marked increase in putrescine content and biosynthesis (while spermine cannot be detected). Differentiation (sclerotium formation), however, is accompanied by a major increase in spermine content.
\end{abstract}

\section{INTRODUCTION}

Polyamines are present in various amounts in all living organisms and have been implicated in the control of growth and development of micro-organisms, mammalian tissues, and plants (Altman, 1989; Bachrach, 1973; Cohen, 1971; Smith, 1985; Stevens, 1981; Tabor \& Tabor, 1984). Polyamines have been shown to interact specifically with nucleic acids and membranes, suggesting a basic regulatory role (Bachrach, 1973; Cohen, 1971; Tabor \& Tabor, 1984). In fungi, changes in the polyamines putrescine and spermidine have been associated with a variety of morphological changes (Stevens, 1981; Stevens \& Winter, 1979). Usually, the levels of putrescine and spermidine increase when morphogenesis is accompanied by a high rate of cell division, nucleic acid and protein synthesis. This phenomenon was observed with respect to germination of zoospores of Blastocladiella emersonii (Mennucci et al., 1975), Achlya ambisexualis (Wright et al., 1982), spherules of Physarum polycephalum (Mitchell \& Rusch,

\footnotetext{
Abbreviations: ODC, ornithine decarboxylase; ADC, arginine decarboxylase; $\alpha$-DMFO, $\alpha$-difluoromethylornithine.
} 
1973), ascospores of yeasts (Brawley \& Ferro, 1979), and during morphogenesis of Mucor racemosus (Inderlied et al., 1980). However, when differentiation occurs without rapid proliferation, polyamine content decreases parallel to a low rate of synthesis of RNA and proteins, as found in fruiting body formation of Physarum polycephalum (Mitchell \& Rusch, 1973). An increase in the activity of ornithine decarboxylase (ODC)(EC 4.1.1.17), a key enzyme in polyamine biosynthesis, accompanies the increase in the rate of macromolecule synthesis and growth, in micro-organisms and in mammalian tissues (Tabor \& Tabor, 1984). Considerable changes in polyamine content and biosynthesis, including the activity of both ODC and arginine decarboxylase (ADC)(EC 4.1.1.19), were found also to accompany growth and certain stress responses of plant tissues (Altman, 1989; Smith, 1985). Polyamines may play a role in stabilization of plant cell membranes (Smith, 1985) and were found bound to membrane phospholipids in Escherichia coli (Peter et al., 1979). Recently, it was reported (Rajam \& Galston, 1985) that $\alpha$-difluoromethylornithine ( $\alpha$-DMFO), the specific inhibitor of ODC, inhibited mycelial growth of four phytopathogenic fungi.

Morphogenesis in the plant pathogen Sclerotium rolfsii has been studied for the last two decades (Chet \& Henis, 1975). Synchronous formation of sclerotia can be triggered by certain supplements to the growth medium (Chet et al., 1966; Chet \& Henis, 1975; Kritzman et al., 1976; Okon et al., 1973), or by changing the proportions between aerial and submerged mycelium (Hadar et al., 1981). However, no information is available concerning polyamine metabolism during sclerotial morphogenesis and mycelium growth in $S$. rolfsii. In this study we present evidence that formation and germination of sclerotia, as well as mycelium growth of $S$. rolfsii, are accompanied by marked changes in the content of endogenous putrescine, spermidine and spermine, and in the activity of ODC.

\section{METHODS}

Growth of Sclerotium rolfsii. (a) Solid medium. Sclerotium rolfsii type A ATCC 26325 (Chet \& Henis, 1975) was grown at $30^{\circ} \mathrm{C}$ on a cellophane membrane in Petri dishes $(8.5 \mathrm{~cm}$ diameter) containing $15 \mathrm{ml}$ synthetic medium (Okon et al., 1973). The plates were inoculated in the centre with agar discs $(0.5 \mathrm{~cm}$ in diameter) covered with fungal mycelium which had been cut from a 3-d-old colony. Mycelia from solid medium were harvested by cutting only the marginal $1 \mathrm{~cm}$ of mycelium. Sclerotial initials were removed from the fungal colony, and only those which had a white colour were selected. The dark brown sclerotia were defined as mature sclerotia. Samples from each morphological structure (mycelium, white initials, and mature sclerotia) were taken for determination of polyamine content and enzyme activity. Where mentioned, various compounds were added directly to the agar medium.

(b) Submerged culture. Flasks containing $50 \mathrm{ml}$ of the same medium were inoculated with $1 \mathrm{ml}$ of suspension containing $10 \mathrm{mg}$ dry wt mycelium ml $\mathrm{m}^{-1}$ and incubated at $30^{\circ} \mathrm{C}$ on a rotary shaker (New Brunswick Scientific) at 150 r.p.m. for $3 \mathrm{~d}$. Inoculum was prepared by homogenizing mycelium in the culture flasks with an Ultra-Turrax homogenizer (Janke \& Kunkel, FRG) operated at one-third of maximum speed (Zweck et al., 1978). Mycelium from liquid medium was separated from the extracellular polysaccharide by centrifugation at $12000 \mathrm{~g}$ for $20 \mathrm{~min}$. Samples of mycelium were taken for determination of polyamine content and enzyme activity.

Determination of biomass, glucose and protein. Fungal material was separated from the growth medium, washed twice with cold $50 \mathrm{~mm}$-potassium phosphate buffer ( $\mathrm{pH} \mathrm{7.4)}$ and dried at $70^{\circ} \mathrm{C}$ to constant weight. Glucose was determined using glucose oxidase reagent (Sigma), according to the manufacturer's directions. Protein in the extracts was determined by the Lowry method, after precipitation with $7 \%(\mathrm{v} / \mathrm{v}) \mathrm{HClO}_{4}$ and hydrolysis in $1 \mathrm{M}-\mathrm{NaOH}$.

Polyamine determination. Polyamines were analysed according to Friedman et al. (1982), with some modifications. Free polyamines were extracted by homogenizing 100-500 mg fresh weight of fungal material with $5 \mathrm{ml}$ cold $4 \%(\mathrm{v} / \mathrm{v}) \mathrm{HClO}_{4}$ for $5 \mathrm{~min}$ in an Ultra-Turrax homogenizer. The extract was centrifuged for $25 \mathrm{~min}$ at $15000 \mathrm{~g}$ and the supernatant was used for polyamine determination by the dansyl reaction. Sufficient $\mathrm{Na}_{2} \mathrm{CO}_{3}$ was added to a $0.2 \mathrm{ml}$ sample of the $\mathrm{HClO}_{4}$ extract to bring it to a $\mathrm{pH}$ of approximately $7 \cdot 0$, followed by an overnight incubation in the dark (at room temperature) with $0.4 \mathrm{ml}$ dansyl chloride ( $30 \mathrm{mg} \mathrm{ml}^{-1}$ in acetone). Excess dansyl chloride was removed by a 30 min incubation with $0.1 \mathrm{ml} \mathrm{L}$-proline $\left(100 \mathrm{mg} \mathrm{ml}^{-1}\right)$, after which dansylated polyamines were extracted in $0.5 \mathrm{ml}$ toluene. Samples $(20-50 \mu \mathrm{l})$ of toluene extract were spotted on activated $(1 \mathrm{~h}$ at $110^{\circ} \mathrm{C}$ ) TLC plates precoated with $375 \mu \mathrm{m}$ silica gel G-60 (Merck), and co-chromatographed with dansylated polyamine standards. Plates were developed in ethyl acetate/cyclohexane $(2: 3, \mathrm{v} / \mathrm{v})$ and measured in a PerkinElmer fluorescence spectrophotometer 204 (excitation at $365 \mathrm{~nm}$, emission at $485 \mathrm{~nm}$ ) The content of individual polyamines is presented as nmol (g dry wt $)^{-1}$. 
Extraction and assay of arginine decarboxylase and ornithine decarboxylase. Fungal material was harvested and homogenized in a prechilled mortar with a pestle [100-500 mg fresh weight ( $2 \mathrm{ml}$ medium $\left.)^{-1}\right]$, for determination of ADC and ODC activity according to Altman et al. (1982). Extraction medium consisted of 10 mM-potassium phosphate buffer ( $\mathrm{pH} \mathrm{7.2),0.1} \mathrm{mm-dithiothreitol,} 1 \mathrm{~mm}$-pyridoxal-5-phosphate, and $20 \mathrm{~mm}-\mathrm{Na}_{2}$ EDTA. The extracts were centrifuged at $12000 \mathrm{~g}$ for $20 \mathrm{~min}$, and the supernatant, hereafter referred to as crude enzyme, was used immediately. The enzyme reaction was started by adding $100 \mu \mathrm{l}$ crude enzyme to a vial containing $150 \mu \mathrm{l}$ of the extraction medium and $50 \mu \mathrm{l} \mathrm{DL}-\left[1^{-14} \mathrm{C}\right]$ arginine hydrochloride (Amersham, $0 \cdot 125 \mu \mathrm{Ci}, 20 \mathrm{mCi} \mathrm{mmol}^{-1}$, $740 \mathrm{MBq} \mathrm{mmol}^{-1}$ ) or $\mathrm{L}-\left[1-^{-14} \mathrm{C}\right]$ ornithine hydrochloride (Amersham, $0 \cdot 125 \mu \mathrm{Ci}, 59 \mathrm{mCi} \mathrm{mmol}{ }^{-1} ; 2183 \mathrm{MBq}$ $\mathrm{mmol}^{-1}$ ) for ADC or ODC assay, respectively. The vials were then capped with rubber stoppers fitted with plastic centre wells (Kontes Glass Co.) containing 0.2 ml Soluen-100 (Packard) on a Whatman no. 1 paper wick. The reaction was allowed to proceed for $60 \mathrm{~min}$ at $37^{\circ} \mathrm{C}$ in a shaking water bath, and was terminated by injecting $0.2 \mathrm{ml} 4 \% \mathrm{HClO}_{4}$ into the reaction mixture. After an additional $30 \mathrm{~min}$ shaking, the centre wells were removed and placed in vials with $10 \mathrm{ml}$ toluene/PPO/POPOP scintillation mixture. Blank values were obtained by using boiled crude enzyme. ADC and ODC activities are presented as nmol liberated ${ }^{14} \mathrm{CO}_{2} \mathrm{~h}^{-1}$ (mg protein) $)^{-1}$.

\section{RESULTS}

\section{Changes in polyamine content and ODC activity during $S$. rolfsii growth in submerged culture}

Growth of $S$. rolfsii in submerged culture continued at a linear rate up to $80 \mathrm{~h}$, when glucose concentration in the medium was about $23 \%$ of its initial level. Thereafter, growth rate decreased considerably, and finally ceased (Fig. 1a). Upon glucose exhaustion, at about $120 \mathrm{~h}$ (Shapira et al., 1986), the culture develops the potential for sclerotium formation (Hadar et al., 1981). Fungal growth was accompanied by considerable changes in the content of free polyamines (Fig. $1 b$ ). Putrescine content, which was especially high during the lag and in the beginning of the exponential phase (the first $50 \mathrm{~h}$ ), declined dramatically during the second part of the exponential phase and reached a constant low level throughout the stationary growth phase $(80-160 \mathrm{~h})$. Spermidine content was constant during the entire growth period. Spermine was detected only after all the glucose was consumed. ODC activity was highly correlated with putrescine content (Fig. 1c). Thus, the lag phase and the first part of the exponential phase was characterized by high ODC activity, which later declined and reached very low levels throughout the stationary phase. ADC activity could not be detected during any stage of $S$. rolfsii growth in submerged culture.

\section{Changes in polyamine content during sclerotium formation and sclerotium germination on solid medium}

Synchonization of sclerotium formation occurs when a $S$. rolfsii colony is transferred to a solid medium supplemented with $10^{-5}$ M-L-threonine (Kritzman et al., 1976). Several culture samples which represented the various morphological stages, were collected and analysed for polyamine content during the transition from mycelium to mature sclerotia (Fig. 2a). High levels of putrescine $\left[11 \mathrm{nmol}(\mathrm{g} \text { dry } w \mathrm{t})^{-1}\right]$ and spermidine $\left[13 \mathrm{nmol}(\mathrm{g} \text { dry } \mathrm{wt})^{-1}\right]$ were found in mycelium grown on solid medium. The transition from mycelia, through sclerotial initials (white initials), to mature sclerotia, was accompanied by a dramatic decrease in putrescine content and a more gradual decrease in spermidine. Spermine was not detected in the mycelium, but its content increased considerably towards sclerotium formation and maturation, to concentrations well above those of putrescine. However, a mirror image was apparent upon sclerotium germination (Fig. $2 b$ ): putrescine and spermidine content increased rapidly during sclerotial germination and mycelium growth, while spermine decreased and could not be detected $30 \mathrm{~h}$ after germination (Fig. 2b).

\section{Effects of $\alpha-D F M O$, polyamines and cycloheximide on $S$. rolfsii growth and germination and on $O D C$ activity}

Addition of $\alpha$-DFMO to the growth medium did not affect sclerotial formation, but it inhibited mycelial linear growth (Fig. $3 a$ ) and sclerotial germination (Fig. $4 a$ ). The untreated mycelium reached the edge of a Petri dish within $80 \mathrm{~h}$, while the colony grown in the presence of $10^{-3} \mathrm{M}-\alpha$-DFMO hardly reached half that distance (Fig. $3 a$ ). ODC activity was high during the 


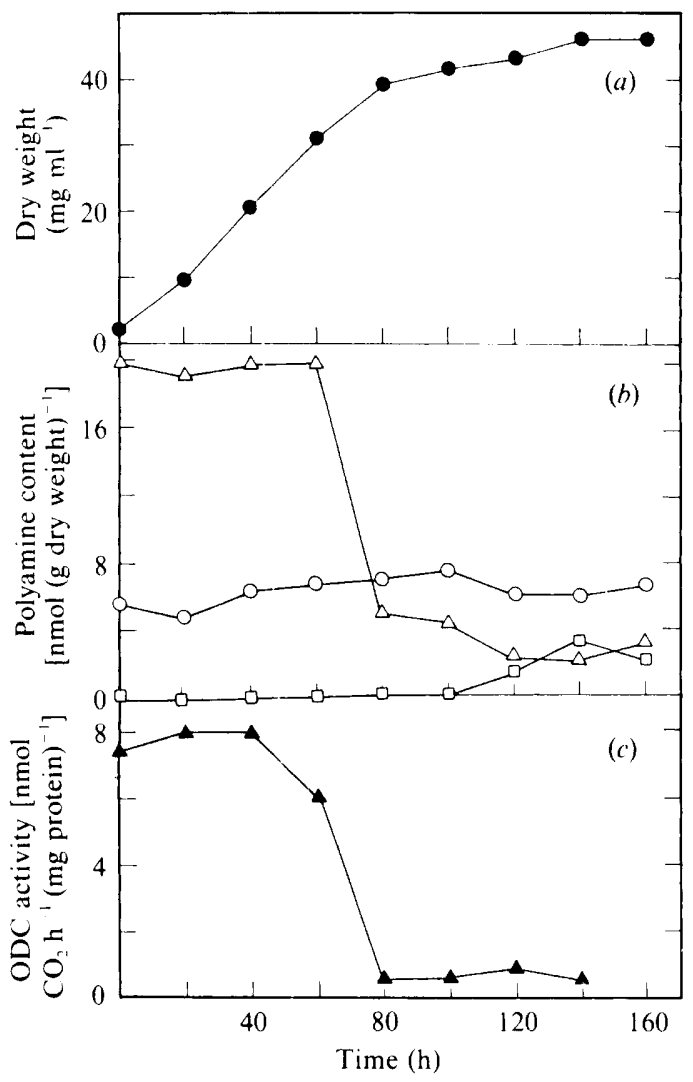

Fig. 1. (a) Mycelial growth ( $(\bullet)$, (b) polyamine content and (c) ODC activity $(\boldsymbol{\Lambda})$ of $S$. rolfsii in submerged culture. $\triangle$, Putrescine; $\bigcirc$, spermidine; $\square$, spermine.

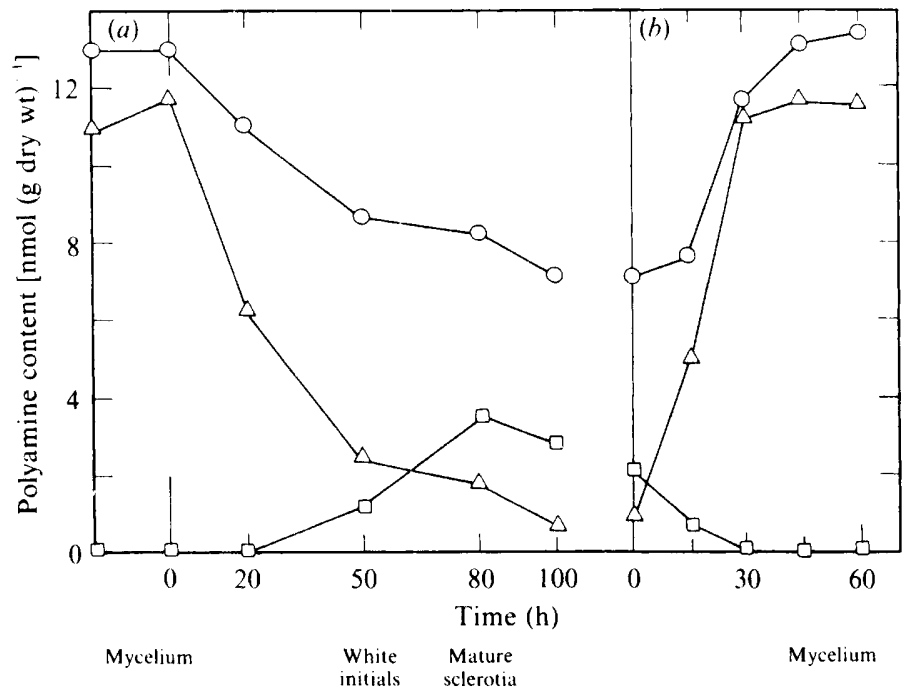

Fig. 2. Changes in polyamine content during formation and germination of sclerotia of $S$. rolfsii grown in solid medium. (a) Maturation of mycelium and sclerotium formation; $(b)$ germination of mature sclerotia. $\triangle$, Putrescine; $O$, spermidine; $\square$, spermine. 


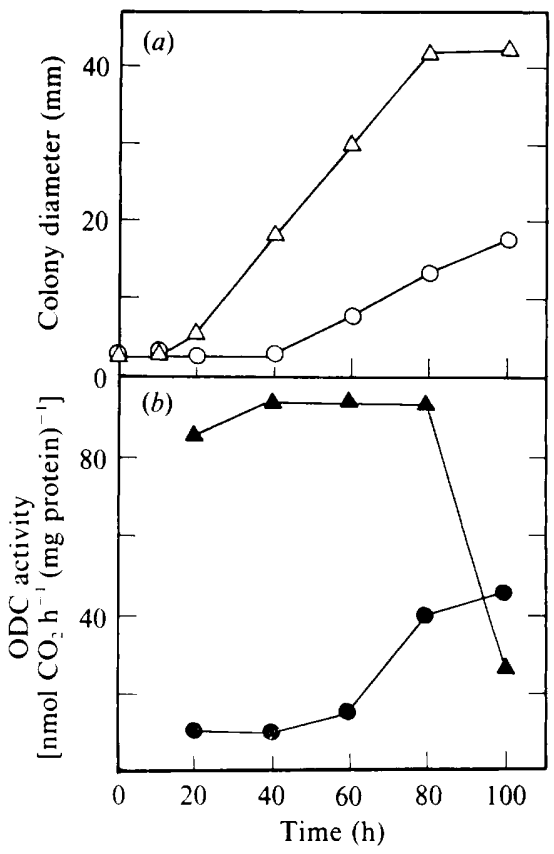

Fig. 3

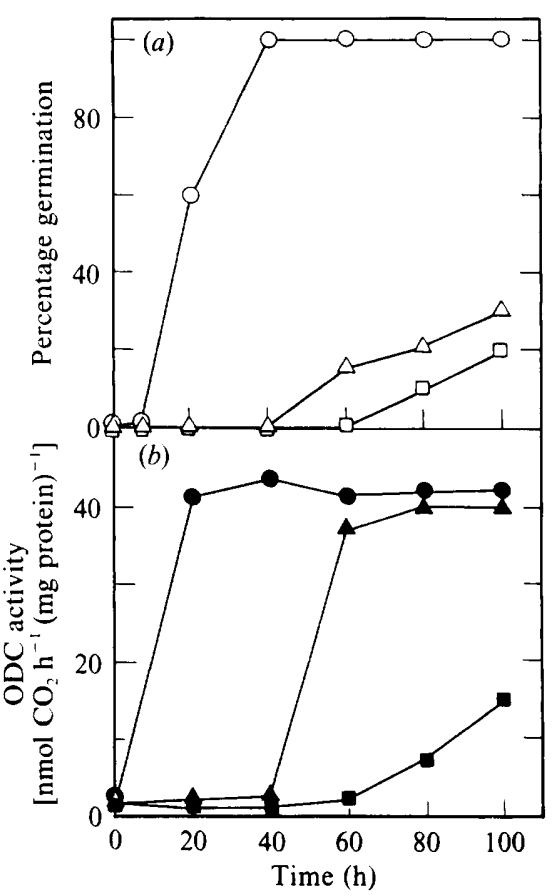

Fig. 4

Fig. 3. Effect of $\alpha$-DFMO (1 mM) on (a) mycelium growth and (b) ODC activity in $S$. rolfsii grown on a solid medium. $\triangle$. $\Delta$, Control; $0,0, \alpha$-DFMO.

Fig. 4. Effect of $\alpha$-DFMO (1 mM) and cycloheximide $\left(20 \mu \mathrm{g} \mathrm{ml}^{-1}\right)$ on $(a)$ sclerotial germination and $(b)$ ODC activity of $S$, rolfsii grown on a solid medium. $O,-$, Control; $\square, \square, \alpha-D F M O ; \triangle, \Delta$, cycloheximide.

Table 1. Inhibition of $S$. rolfsii linear growth and $O D C$ activity by $\alpha-D F M O$, and its reversal by putrescine

Culture time (h) is indicated. Numbers in each column accompanied by the same letter do not differ significantly at the $5 \%$ probability level, using Duncan's multiple-range test.

\begin{tabular}{|c|c|c|c|c|}
\hline \multirow{2}{*}{$\begin{array}{l}\text { Addition to } \\
\text { medium }\end{array}$} & \multicolumn{2}{|c|}{ Colony diameter $(\mathrm{mm})$} & \multicolumn{2}{|c|}{$\begin{array}{c}\text { ODC activity } \\
{\left[\mathrm{nmol} \mathrm{CO}_{2} \mathrm{~h}^{-1}(\text { mg protein })^{-1}\right]}\end{array}$} \\
\hline & $40 \mathrm{~h}$ & $80 \mathrm{~h}$ & $40 \mathrm{~h}$ & $80 \mathrm{~h}$ \\
\hline None & $35^{a}$ & $85^{a}$ & $45^{b}$ & $45^{b}$ \\
\hline$\alpha$-DFMO (1 mM) & $0^{b}$ & $25^{b}$ & $0^{c}$ & $20^{c}$ \\
\hline $\begin{array}{r}\alpha \text {-DFMO }(1 \mathrm{~mm})+ \\
\text { putrescine }(1 \mathrm{~mm})\end{array}$ & $37^{a}$ & $83^{a}$ & $44^{b}$ & $48^{a b}$ \\
\hline Putrescine (1 mM) & $35^{a}$ & $81^{a}$ & $53^{a}$ & $54^{a}$ \\
\hline Putrescine (10 mM) & $0^{b}$ & $5^{c}$ & $0^{c}$ & $0^{d}$ \\
\hline
\end{tabular}

entire growth period up to $80 \mathrm{~h}$ but was almost totally inhibited by $\alpha$-DFMO during the initial $60 \mathrm{~h}$ (Fig. $3 b$ ). After $80 \mathrm{~h}$ of growth, the control colony reached the rim of the Petri dish (cessation of linear growth), and this was accompanied by a marked decrease in ODC activity. The colony morphology of $S$. rolfsii was also affected by the presence of $\alpha$-DFMO: instead of a typical fan-like growth, it was characterized by a compact and condensed mycelium (not shown).

The addition of $1 \mathrm{~mm}$-putrescine to the growth medium completely reversed the inhibitory effect of $\alpha$-DFMO on both ODC activity and mycelial growth (Table 1). Putrescine alone 
( $1 \mathrm{~mm}$ ), did not affect growth rate but caused a slight increase in ODC activity. The addition of $10 \mathrm{~mm}$-putrescine was toxic to $S$. rolfsii (Table 1). Addition of spermine at $10 \mathrm{~mm}$ and $1 \mathrm{~mm}$ did not affect fungal linear growth, but increased the number of sclerotia by $35-40 \%$ (data not presented).

In addition to its inhibitory effect on the growth of $S$. rolfsii, $\alpha$-DFMO was also found to be involved in sclerotial germination (Fig. $4 a$ ): germination in control medium was completed within $40 \mathrm{~h}$, while germination in the presence of $10^{-3} \mathrm{M}-\alpha$-DFMO was delayed for almost $60 \mathrm{~h}$, and only $20 \%$ of the sclerotia germinated. The inhibitory effect of $\alpha$-DFMO on sclerotial germination was paralleled by its marked effect on ODC activity (Fig. $4 b$ ).

A high rate of protein synthesis is associated with rapid biosynthesis of polyamines in microorganisms, as well as in plants and mammalian tissue (Bachrach, 1973; Cohen, 1971; Tabor \& Tabor, 1984). Cycloheximide, which has been shown previously to inhibit sclerotium formation and protein synthesis (Okon et al., 1973), also inhibited sclerotial germination, but its initial inhibition of ODC activity was relieved as soon as sclerotia began to germinate (Fig. $4 b$ ).

\section{DISCUSSION}

Changes in the endogenous level of polyamines and in the activity of several key enzymes of polyamine biosynthesis usually precede or accompany growth and morphological changes in many organisms, including fungi (Bachrach, 1973; Cohen, 1971; Heby, 1981; Smith, 1985; Tabor \& Tabor, 1984). Spore germination in fungi is characterized by accelerated synthesis of polyamines (Kim, 1971; McDougall et al., 1977). The changes which were found in the endogenous levels of polyamines during sclerotial germination of $S$. rolfsii are similar to those occurring in spore germination of other fungi. The formation of fruiting bodies in several fungal species is characterized by a simultaneous decrease in levels of polyamines and in the synthesis of macromolecules (Mitchell \& Rusch, 1973). Similarly, our data show that sclerotial formation in $S$. rolfsii is accompanied by a rapid decrease in polyamine level (Fig. $2 a$ ). Indeed, Willetts (1978) analysed the evolutionary sources of sclerotia in several fungi, and concluded that fungal sclerotia are degenerated fruiting bodies.

The similarity between the polyamine-related morphogenetic changes in $S$. rolfsii and those observed in other fungi was also established by the use of $\alpha$-DFMO, a specific inhibitor of ODC - the key enzyme in polyamine biosynthesis in fungi (Stevens \& Winter, 1979; Tabor \& Tabor, 1984). Thus, sclerotium formation in $S$. rolfsii was not affected by $\alpha$-DFMO while sclerotial germination and mycelial growth rate were inhibited (Figs $3 a$ and $4 a$ ). The inhibitory effect of $\alpha$-DFMO on growth of several fungi was recently described (Rajam \& Galston, 1985). In $S$. rolfsii, inhibition of sclerotial germination and mycelial growth is reversed by the addition of putrescine to the growth medium, indicating that putrescine biosynthesis is essential for these stages in the life cycle of the fungus (Table 1). Indeed, a large amount of experimental data show a close correlation between high rate of ODC activity, polyamine accumulation and macromolecular synthesis and growth in many organisms (Bachrach, 1973; Cohen, 1971; Smith, 1985; Tabor \& Tabor, 1984). It has been suggested that polyamines, and perhaps ODC itself, play an important role in mammalian cell proliferation and differentiation (Heby, 1981). Several studies indicate that the half life of ODC changes throughout cell growth and differentiation, and that the enzyme may be stabilized at later growth stages (Tabor \& Tabor, 1984). This may partially explain the relief of cycloheximide-induced ODC inhibition in germinating sclerotia (Fig. 4).

Changes in polyamines are related to the various developmental stages in the life cycle of fungi (Stevens \& Winter, 1979). It is noteworthy that $S$. rolfsii sclerotia contain spermine, which was not detected in germinating sclerotia or in the fungal mycelium when grown on a solid medium (Fig. 2a,b). Moreover, the major decrease in putrescine level, and the appearance of spermine in submerged culture of $S$. rolfsii, occurred when the fungus developed the potential for sclerotium production. Also, addition of spermine to the medium increased the number of sclerotia (Table 2). Some studies have suggested that spermine is absent in filamentous fungi 
(Nickerson, et al., 1977), while others point to the fact that the presence of spermine is unlikely to be related to the growth form (Stevens, 1981). The present data suggest that the function of $S$. rolfsii sclerotia as resting bodies is correlated with an increase in spermine content. It has yet to be established whether a causal relationship indeed exists.

This research was partially supported by grants from the United States-Israel (Binational) Agricultural Research and Development Fund (BARD) to A. A. and I. C. We thank Dr P. P. McCann, Merrel-Dow Research Institute, for a gift of DFMO and DFMA. The assistance of Mrs N. Levin and R. Guvrin is gratefully acknowledged.

\section{REFERENCES}

Altman, A. (1989). Polyamines and plant hormones. In The Physiology of Polyamines, vol 2. Edited by U. Bachrach \& Y. M. Heimer. Boca Raton, Fla: CRC Press (in the Press).

Altman, A., Friedman, R. \& Levin, N. (1982). Arginine and ornithine decarboxylases, the polyamine biosynthetic enzymes of mung bean seedlings. Plant Physiology 69, 876-879.

BACHRACH, U. (1973). Function of Naturally Occurring Polyamines. New York: Academic Press.

Brawley, J. \& Ferro, A. J. (1979). Polyamine biosynthesis during germination of yeast ascospores. Journal of Bacteriology 140, 649-654.

Chet, I. \& Henis, Y. (1975). Sclerotial morphogenesis in fungi. Annual Review of Phytopathology 13, 169 192.

Chet, I., Henis, Y. \& Mitchell, R. (1966). The morphogenic effect of sulphur amino acids, glutathione and iodoacetate on Sclerotium rolfsii. Journal of General Microbiology 45, 541-546.

CoHen, S. S. (1971). Introduction to the Polyamines. Englewood Cliffs: Prentice-Hall.

Friedman, R., Altman, A. \& Bachrach, U. (1982). Polyamines and root formation in mung bean hypocotyl cuttings. I. Effects of exogenous compounds and changes in endogenous polyamine content. Plant Physiology 70, 844-848.

Hadar, Y., Henis, Y. \& CheT, I. (1981). The potential for the formation of sclerotia in submerged mycelium of Sclerotium rolfsii. Journal of General Microbiology 122, 137-141.

HEBY, O. (1981). Role of polyamines in the control of cell proliferation and differentiation. Differentiation 19, 1-20.

INDERLIEd, C. B., Cihlar, R. L. \& Sypherd, P. S. (1980). Regulation of ornithine decarboxylase during morphogenesis of Mucor racemosus. Journal of Bacteriology 141, 699-706.

KIM, W. K. (1971). Folate and polyamine content of undifferentiated and differentiated wheat stem rust uredosporelings. Canadian Journal of Botany 49, 1119-1122.

Kritzman, G., Okon, Y., Henis, Y. \& Chet, I. (1976). Metabolism of L-threonine and its relationship to sclerotium formation in Sclerotium rolfsii. Journal of General Microbiology 95, 78-86.

McDougall, K. J., Deters, J. \& Miskimen, J. (1977). Isolation of putrescine-requiring mutants of Neurospora crassa. Antonie van Leeuwenhoek 43, 143-151.
Mennucci, L., Rojas, S. \& Camargo, E. P. (1975). Polyamines and ornithine decarboxylase activity during growth and differentiation in Blastocladiella emersonii. Biochimica et biophysica acta 404, 249-256.

Mitchell, J. L. A. \& RusCh, H. P. (1973). Regulation of polyamine synthesis in Physarum polyephalum during growth and differentiation. Biochimica et biophysica acta 297, 503-516.

Nickerson, K. W., Dunnkel, L. D. \& VanEtTen, J. L. (1977). Absence of spermine in filamentous fungi. Journal of Bacteriology 129, 173-176.

OKon, Y., Chet, I. \& Henis, Y. (1973). Effect of lactose, ethanol and cycloheximide on the translocation pattern of radioactive compounds and sclerotium formation in Sclerotium rolfsii. Journal of General Microbiology 81, 145-149.

Peter, H. W., Gunter, N. \& Seiler, N. (1979). Interrelations between polyamines and phospholipids in Escherichia coli. FEMS Microbiology Letters 5, 389-393.

Rajam, M. V. \& Galston, A. M. (1985). The effect of some polyamine biosynthetic inhibitors on growth and morphology of phytopathogenic fungi. Plant and Cell Physiology 26, 683-692.

Shapira, R., Pines, M., Chet, I. \& Henis, Y. (1986). Regulation of glycogen synthase in Sclerotium rolfsii. Journal of General Microbiology 132, 765-770.

SmIth, T. T. (1985). Polyamines. Annual Review of Plant Physiology 36, 117-143.

StEVENS, L. (1981). Regulation of the biosynthesis of putrescine, spermidine and spermine in fungi. Medical Biology 59, 309-313.

Stevens, L. \& Winter, M. D. (1979). Spermine, spermidine and putrescine in fungal development. Advances in Microbiological Physiology 19, 63-148.

TABOR, C. W. \& TABOR, H. (1984). Polyamines. Annual Review of Biochemistry 53, 749-790.

Willets, H. J. (1978). Sclerotium formation, In The Filamentous Fungi, pp. 197-211. London: Academic Press.

Wright, J. M., Gulliver, W. P., Michalski, C. J. \& BOYLE, S. M. (1982). Ornithine decarboxylase activity and polyamine content during zoospore germination and hormone-induced sexual differentiation of Achlya ambisexualis. Journal of General Microbiology 128, 1509-1515.

ZWeCK, S., Hutterman, A. \& Chet, I. (1978). A convenient method for preparing inocula of homogenized mycelia. Experimental Mycology 21, 377-379. 